\title{
Barium ferrite nanoparticles prepared by self-propagating low-temperature combustion method and its characterization
}

\author{
P M PRITHVIRAJ SWAMY, S BASAVARAJA $\dagger$, VIJAYANAND HAVANOOR, \\ N V SRINIVAS RAO ${ }^{\dagger \dagger}$, R NIJAGUNAPPA ${ }^{\dagger \dagger}$ and A VENKATARAMAN* \\ Materials Chemistry Laboratory, Department of Materials Science, Gulbarga University, Gulbarga 585 106, India \\ †Present address: Veeco-India Nanotechnology Laboratory, \\ Jawaharlal Nehru Centre for Advanced Scientific Research, Jakkur, Bangalore 560 064, India \\ ${ }^{\dagger}$ R\&D Centre Premier Explosives Pvt. Ltd., Hyderabad 500 015, India \\ ${ }^{\dagger \dagger}$ Department of Environmental Sciences, Gulbarga University, Gulbarga 585 106, India
}

MS received 14 April 2010

\begin{abstract}
The barium ferrite particles were prepared using a self-propagating low-temperature combustion method using polyethylene glycol (PEG) as a fuel. The process was investigated with simultaneous thermogravimetric-differential thermal analysis (TG-DTA). The crystalline structure, morphology and the magnetic properties of the barium ferrite particles were studied by means of X-ray diffraction (XRD), scanning electron microscopy (SEM), transmission electron microscopy (TEM) and SQUID susceptometer. The results show that the ignition temperature of PEG is lower compared with other combustion methods and gives nanocrystalline barium ferrite.
\end{abstract}

Keywords. Barium ferrite; self-propagating combustion method; magnetic property; X-ray diffraction; morphology.

\section{Introduction}

$\mathrm{BaFe}_{12} \mathrm{O}_{19}$ is currently a magnetic material of great scientific and technological interest, because of its relatively high Curie temperature, high coercive force and high magnetic anisotropy field, as well as its excellent chemical stability and corrosion resistivity (Kojima and Wohlfarth 1982). In the past decade, there has been an increasing interest in methods for the preparation of fine particles of barium hexaferrites, because of the materials emerging application in perpendicular magnetic recording media and microwave-absorbing devices. It should be noted that particle characteristics, i.e. homogeneity, morphology and magnetic properties, are influenced significantly by the synthesis method (Benito et al 2001).

Conventionally, the solid-state reaction for preparing barium ferrite powder requires a high calcining temperature $\left(1200-1300^{\circ} \mathrm{C}\right)$ after milling the mixture of ferric oxide and barium carbonate. Furthermore, the milling process results in the introduction of impurities into the material compositions, generation of lattice strains in the molecular structure and production of irregularity in the particle shape. Although the high temperature ensures the formation of barium ferrite, larger particles are also produced in this process (Stablin and Wohlfarth 1982). In

\footnotetext{
*Author for correspondence (raman_chem@rediffmail.com)
}

other words, all of these will have negative impacts on the development of microstructures as well as the magnetic properties of barium ferrite powder. In order to achieve highly homogeneous ultrafine particles and avoid the milling process, different synthesis techniques have been used to prepare $\mathrm{BaFe}_{12} \mathrm{O}_{19}$, such as chemical coprecipitation (Roos 1980; Zheng et al 1989; Jacobo et al 1997), glass crystallization (Shirk and Buessem 1970; Kubo et al 1982; Lucchini et al 1983), hydrothermal (Barb et al 1986), microemulsion (Liu et al 1998) and sol-gel methods (Surig et al 1994; Zhong et al 1997). However, a number of difficulties in obtaining highpurity, ultrafine and homogeneous particles of barium hexaferrite with narrow size distribution have been pointed out by several investigators.

Self-propagating combustion synthesis (Patil et al 1997) has emerged as an important technique for the synthesis and processing of advanced ceramics (structural and functional), catalysts, composites, alloys, intermetallics and nanomaterials. In a self-propagating low-temperature synthesis, an entirely different approach of synthesis is involved, which uses the combustible precursors (redox compounds) and redox mixtures (oxidizer-fuel). It uses low-temperature $\left(<500^{\circ} \mathrm{C}\right)$ initiated gas-producing exothermic reactions that are self-propagating and yield voluminous fine particle oxides in few minutes. This process is characterized by low-temperatures, fast heating rates and short reaction times. These features make self- 
propagating low-temperature synthesis an attractive method for the manufacture of technologically useful materials at lower costs compared with other processes. Some other advantages of combustion synthesis (CS) are: use of relatively simple equipment, a simple preparation method with inexpensive precursors, formation of highpurity products, stabilization of metastable phases and formation of products of virtually any size and shape.

In this paper, we report the synthesis of $\mathrm{BaFe}_{12} \mathrm{O}_{19}$ nanoparticles through a self-propagation low-temperature combustion route employing metal oxalate precursors. In search of a suitable economic fuel, our use of polyethylene glycol (PEG) has given promising results in a single step. Some of the possible reasons for employing PEG in the present study are: Polyethylene glycol has a sharp melting point $\left(62^{\circ} \mathrm{C}\right)$ and decomposition temperatures, and they are widely separated. The carboxylate precursors get well dispersed in the molten polyethylene glycol on its melting. PEG is known to be a good surfactant and a dispersant, and hence, ultrafine and nanomaterials are expected to be formed as the final products on combustion. PEG has alcoholic groups and it burns in air exothermically with precursors to form desired metal oxides/ferrites. In our earlier studies we have successfully used this fuel for the synthesis of $\gamma-\mathrm{Fe}_{2} \mathrm{O}_{3}$ and other metal oxides from different precursors (Venkataraman et al 2001; Lagashetty et al 2005; Basavaraja et al 2007). The formation and structure of barium ferrite nanoparticles was confirmed by powder X-ray diffraction (XRD), size and morphology by employing scanning electron microscopy (SEM) and transmission electron microscopy (TEM) and bonding by Fourier transform infrared (FT-IR) spectroscopy techniques. Magnetic property was studied by SQUID. Our results show that self-propagating combustion is a fast and convenient method in the preparation of nanocrystalline $\mathrm{BaFe}_{12} \mathrm{O}_{19}$.

\section{Experimental}

All the chemicals were of AR grade and were used as received. Double-distilled water was used for preparation of the required solutions.

\subsection{Preparation of metal oxalates}

An equimolar solution of ferrous ammonium sulphate heptahydrate/barium nitrate and oxalic acid were dissolved in minimum quantity of water and was stirred well. The respective metal oxalate precipitate obtained was filtered through sintered glass crucible and was washed with cold distilled water and alcohol until it was free from sulphate/nitrate ions and oxalic acid, and the filtrate was finally washed with dry acetone and then dried under vacuum.

\subsection{Preparation of $\mathrm{BaFe}_{12} \mathrm{O}_{19}$}

The ferrous oxalate and zinc oxalate precursors were mixed with PEG in a weight ratio $1: 1: 5$, respectively, and ground well with a mortar and pestle. The resultant solid was placed in a silica crucible and heated in air. It was observed that initially PEG melted, then frothed and finally ignited to give $\mathrm{BaFe}_{12} \mathrm{O}_{19}$ as a residue. On cooling to room temperature, no traces of carbon impurities were observed in the final residue of $\mathrm{BaFe}_{12} \mathrm{O}_{19}$. As the reaction is fast, i.e. going to completion within $10 \mathrm{~min}$, and ignites auto-catalytically, the exact temperature of the reaction could not be measured. However using a thermocouple the highest temperature of the reaction was found to be around $500^{\circ} \mathrm{C}$. The $\mathrm{BaFe}_{12} \mathrm{O}_{19}$ was then characterized for its structure (employing XRD), morphology (SEM), particle size determination (TEM), etc.

\subsection{Characterization techniques}

Simultaneous thermogravimetric and differential scanning calorimetry (TG/DSC) traces were obtained from Mettlar Teledo Star instruments (Weinheim, Germany) under a dynamic flow of nitrogen at a flow rate of $100 \mathrm{ml} / \mathrm{min}$ and at a heating rate of $10^{\circ} \mathrm{C} / \mathrm{min}$. The XRD pattern was obtained employing a JEOL JDX-8p spectrometer using $\mathrm{CuK} \alpha$ radiation $(\lambda=1.54 \AA)$. The X-ray generator was operated at $30 \mathrm{kV}$ and $20 \mathrm{~mA}$. The scanning range, $2 \theta$, was selected. The scanning speed of $1 \% \mathrm{~min}$ and a chart speed of $20 \mathrm{~mm} / \mathrm{min}$ were used for the precise determination of the lattice parameters. The morphology of the nanoparticles was characterized using coupling JSM-840A scanning electron microscope. The electron microscope was operated at $20 \mathrm{kV}$. The sample was made conducting by the sputtering of gold using a Poloron DC 'sputtering unit' operated at $1.4 \mathrm{kV}$ and 18-20 mA. Transmission electron microscopy (TEM) image was taken using a Philips CM 200 transmission electron microscopy operated at $200 \mathrm{kV}$. For TEM analysis, a droplet of the ultrasonically dispersed samples in ethanol was placed onto an amorphous carbon-coated copper grid and then dried in air. Magnetic susceptibility data were obtained at $300 \mathrm{~K}$ at various applied fields between -50 and $50 \mathrm{kOe}$ by using a SQUID susceptometer with MPMS-5S (Quantum Design Co.).

\section{Results and discussion}

The TG-DTA curve of the precursor (barium oxalate and ferrous oxalate, $1: 1$ ) obtained under $\mathrm{N}_{2}$ atmosphere with a heating rate of $10^{\circ} \mathrm{C} \mathrm{min}^{-1}$ is shown in figure 1 . The curve shows that multistep continuous weight loss occurs from room temperature to $800^{\circ} \mathrm{C}$. These weight losses appeared as exothermic peaks at $70,265,350$ and $500^{\circ} \mathrm{C}$. 


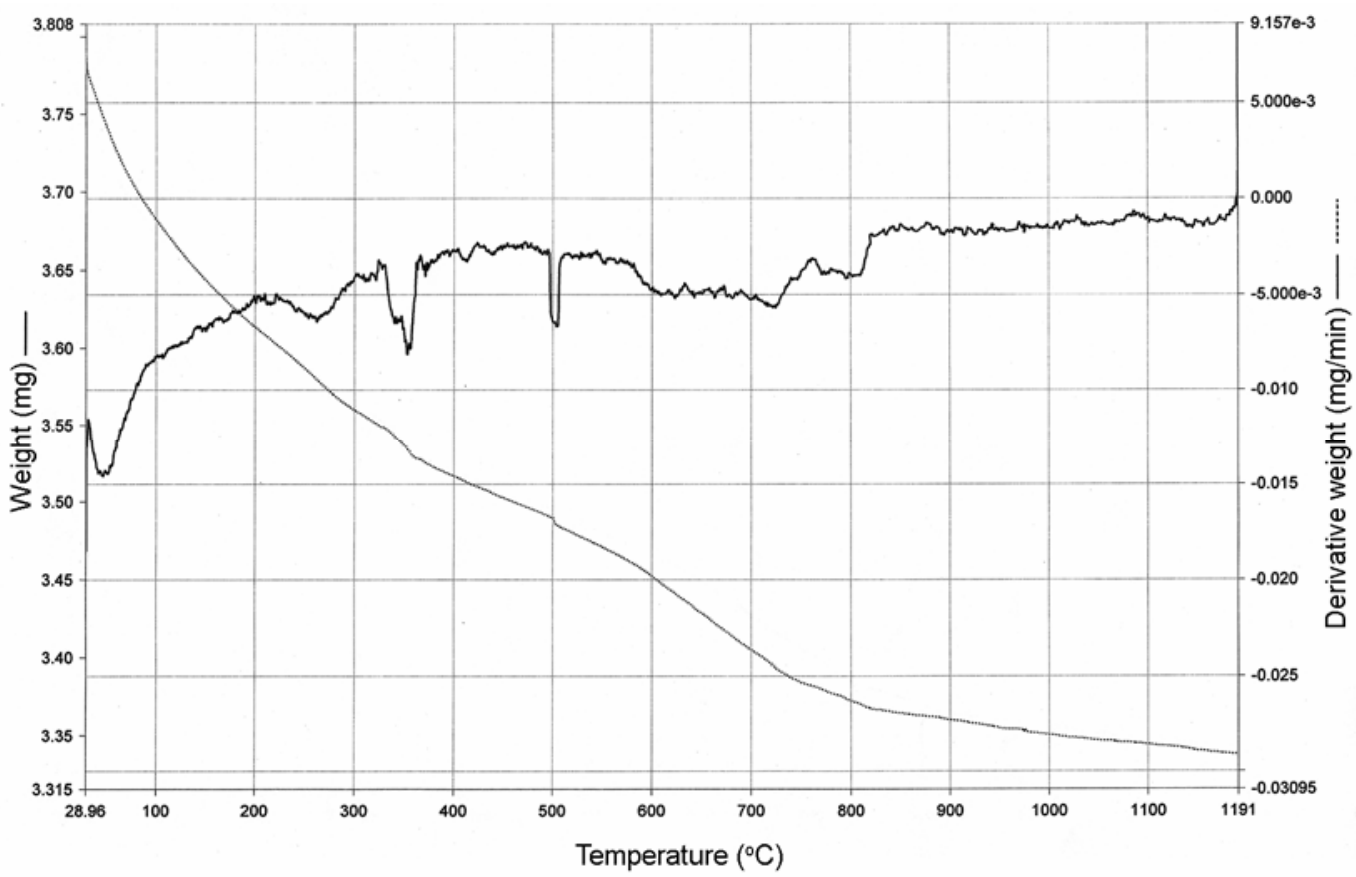

Figure 1. TG-DTA traces of precursors.

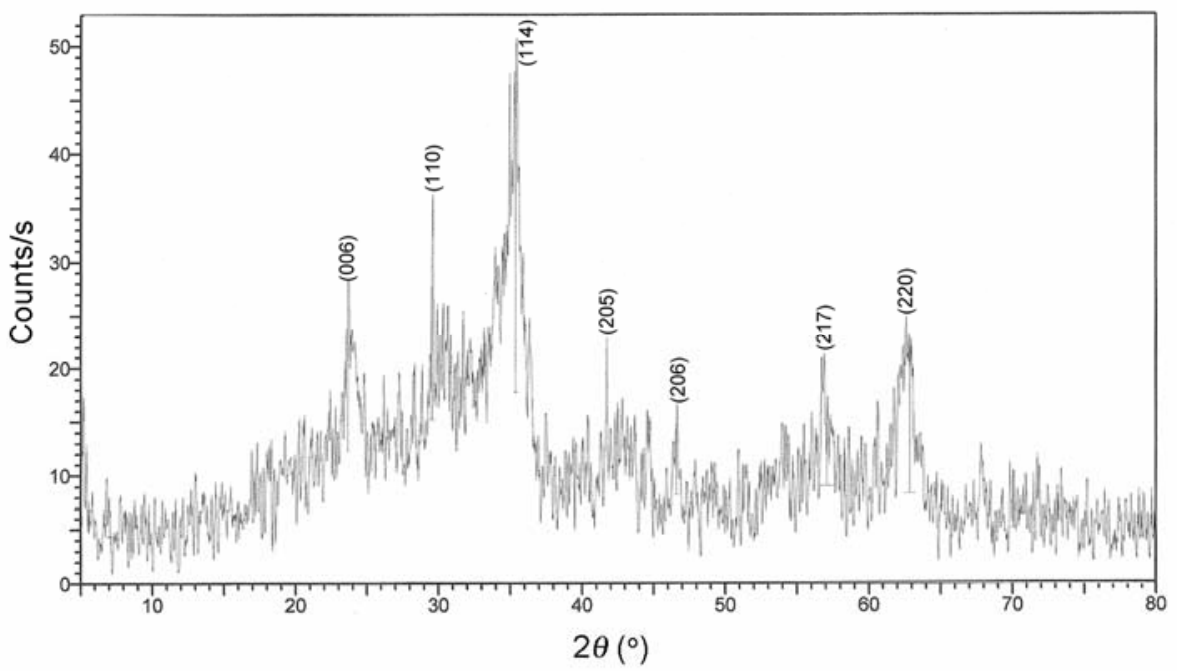

Figure 2. XRD pattern of $\mathrm{BaFe}_{19} \mathrm{O}_{12}$.

The exothermic peak at $70^{\circ} \mathrm{C}$ is attributed to the loss of adsorbed water molecules and other exothermic peaks are because of decomposition of precursor. The endothermic process happens nearly $800^{\circ} \mathrm{C}$, which corresponds to the formation and transition of crystalline phases. The exothermic and endothermic regions in the DTA pattern are consistent with the change regions in the TG pattern. The formation of the barium ferrite can be explained by TG-DTA analysis as follows.

$$
\text { Precursor } \rightarrow \gamma-\mathrm{Fe}_{2} \mathrm{O}_{3}+\mathrm{BaO}\left(200-500^{\circ} \mathrm{C}\right)
$$

$$
\begin{aligned}
& \gamma-\mathrm{Fe}_{2} \mathrm{O}_{3}+\mathrm{BaO} \rightarrow \mathrm{BaFe}_{2} \mathrm{O}_{4}\left(500-600^{\circ} \mathrm{C}\right) \\
& 5 \gamma-\mathrm{Fe}_{2} \mathrm{O}_{3}+\mathrm{BaFe}_{2} \mathrm{O}_{4} \rightarrow \mathrm{BaFe}_{12} \mathrm{O}_{19} \text { (above } 600^{\circ} \mathrm{C} \text { ). }
\end{aligned}
$$

Crystal structure of intermediate $\gamma-\mathrm{Fe}_{2} \mathrm{O}_{3}$ plays an important role in the formation of $\mathrm{BaFe}_{12} \mathrm{O}_{19}$ phase. It is well known that $\gamma-\mathrm{Fe}_{2} \mathrm{O}_{3}$ is a cubic spinel, whose chemical formula is $\mathrm{Fe}\left[\mathrm{Fe}_{5 / 3} \square_{1 / 3}\right] \mathrm{O}_{4}$, where $\square$ stands for a cation hole. This structure is similar to that of ' $\mathrm{S}$ ' block in barium ferrite, thus $\gamma-\mathrm{Fe}_{2} \mathrm{O}_{3}$ can be easily converted into $\mathrm{BaFe}_{12} \mathrm{O}_{19}$ phase. On the other hand, the crystal cell of 
$\gamma-\mathrm{Fe}_{2} \mathrm{O}_{3}$ is orthorhombic hexahedron, which is difficult to transform to $\mathrm{BaFe}_{12} \mathrm{O}_{19}$ phase (Qiu et al 2005).

The TG curve shows no further weight loss above $900^{\circ} \mathrm{C}$, confirming the formation of the stable barium ferrite. The formation of barium ferrite and its phase and purity were determined from the XRD pattern shown in figure 2 . The XRD reveals that the products are monophasic $\mathrm{BaFe}_{12} \mathrm{O}_{19}$ with hexagonal structure; the values in the parenthesis indicate respective miller indices. All these peaks match well with the standard JCPDS file no. 84-0757. No characteristic peaks of impurities of oxides could be detected.

The mean particle diameter was calculated from the XRD pattern according to the line width of the (114)

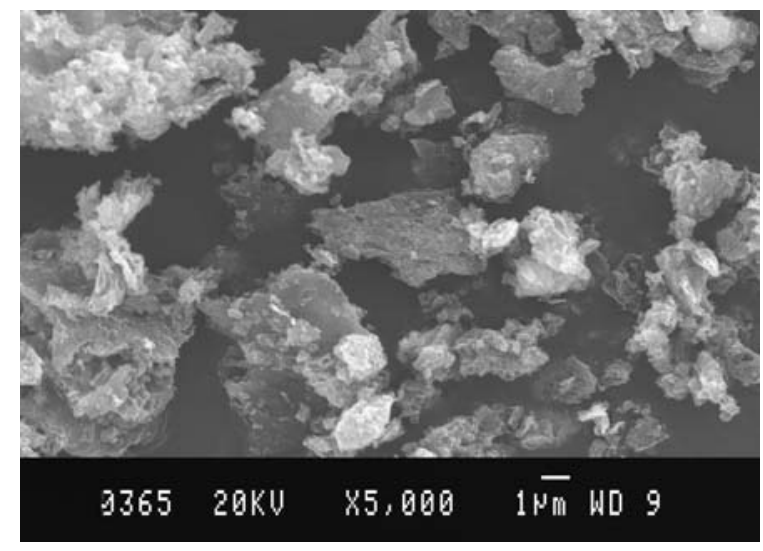

Figure 3. SEM image of $\mathrm{BaFe}_{19} \mathrm{O}_{12}$.

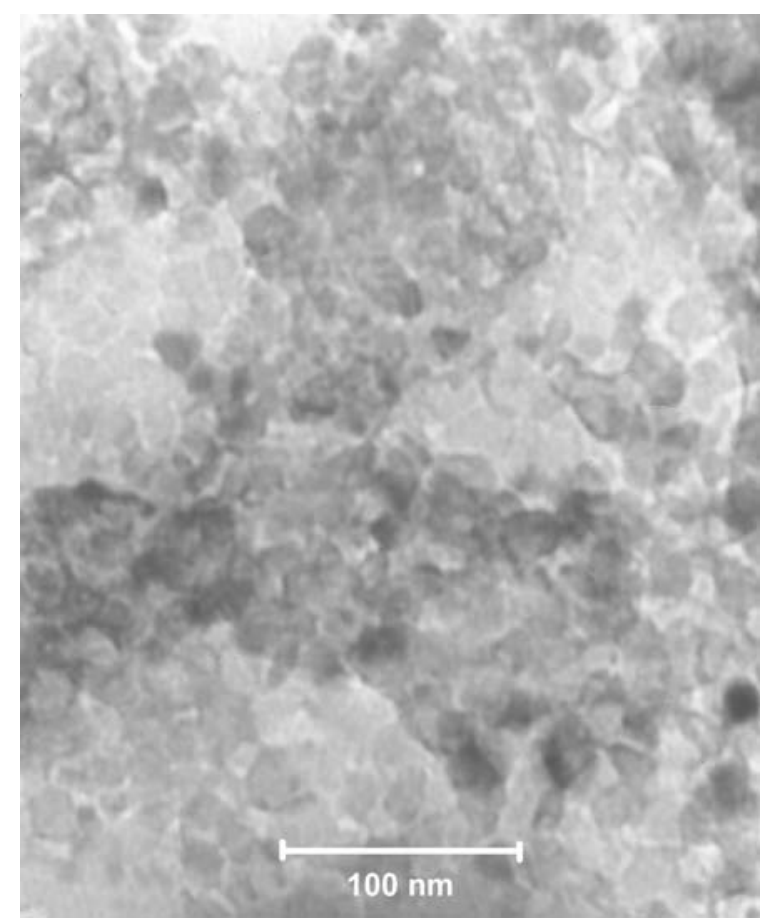

Figure 4. TEM image of $\mathrm{BaFe}_{19} \mathrm{O}_{12}$. plane refraction peak using the following Debye-Scherrer equation (Cornell and Schwertmann 1996):

$$
D=\frac{K \lambda}{\beta_{1 / 2} \cos \theta} .
$$

The equation uses the reference peak width at angle $\theta$, where $\lambda$ is the X-ray wavelength (1.5418 $\AA$ ), $\beta_{1 / 2}$ is the width of the XRD peak at half height and $K$ is the shape factor, about 0.9 for spherical shaped particles. The

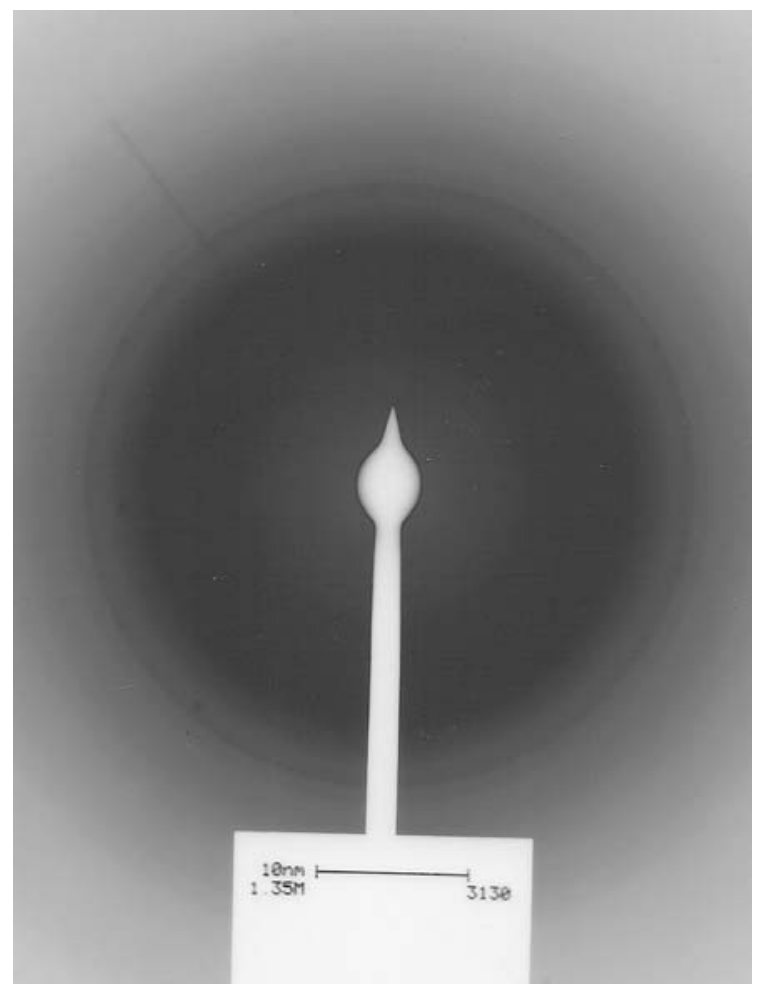

Figure 5. SAED pattern of $\mathrm{BaFe}_{19} \mathrm{O}_{12}$.

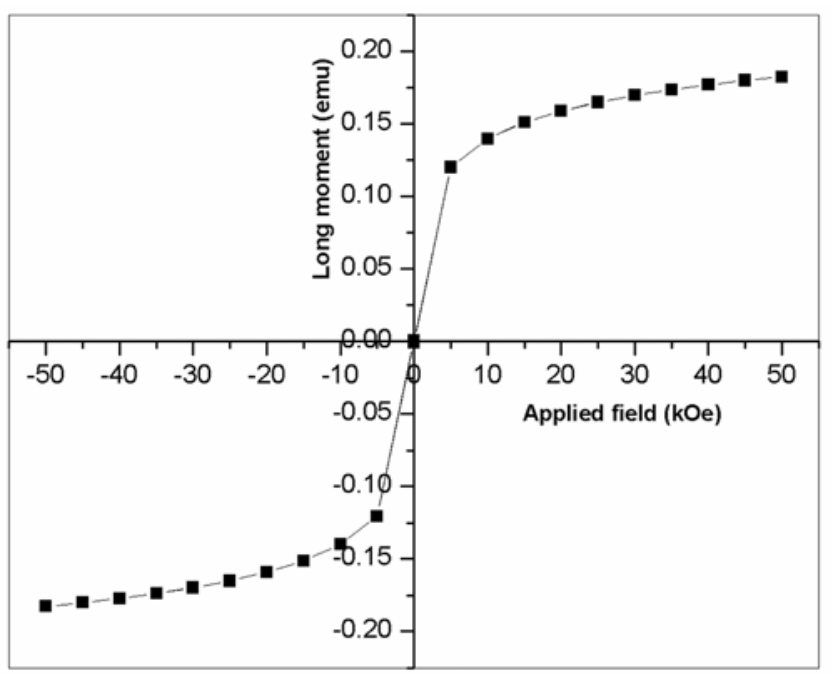

Figure 6. SQUID curve of $\mathrm{BaFe}_{19} \mathrm{O}_{12}$. 
average crystallite size calculated from peak width is about $40 \mathrm{~nm}$, which is in accordance with the TEM results discussed later.

The particle morphology of the synthesized barium ferrite powders is shown in figure 3. The SEM images show irregular shaped plate like structures of micron size. Most of the particles are aggregated, so it is difficult to determine the exact size and shape of the particles. Hence, the exact size and shape of the $\mathrm{BaFe}_{19} \mathrm{O}_{12}$ particles were examined by transmission electron microscopy (TEM) images.

Transmission electron microscopy was employed to confirm the nanocrystalline nature of the as synthesized barium ferrite. The bright field TEM image (figure 4) represents the basic powder morphology of the smallest visible ultrafine particles that might be identified with the crystallites or their aggregates. The whole surface of the grid was covered with barium ferrite nanoparticles as shown in this image. It is clear observing from this image that the nanoparticles are almost hexagonal in structure. The average particle size observed from this image is $35 \mathrm{~nm}$, which is in accordance with the result obtained from the Scherrer formula of XRD.

The corresponding selected area electron diffraction (SAED) for the $\mathrm{BaFe}_{19} \mathrm{O}_{12}$ is shown in figure 5. The ED pattern shows the broad rings without any spots in the pattern. This feature indicates the fine crystalline nature of the sample, which is evident from the TEM images and magnetic studies detailed below.

Magnetization measurements were carried out using a SQUID susceptometer at $300 \mathrm{~K}$ with an applied field of $50 \mathrm{kOe}$. Magnetization versus the applied field plots at $300 \mathrm{~K}$ for $\mathrm{BaFe}_{19} \mathrm{O}_{12}$ is shown in figure 6 . The absence of hysteresis, immeasurable remanence and coercivity, and the non-attainment of saturation at a high applied magnetic field of $50 \mathrm{kOe}$ indicate the presence of superparamagnetic behaviour (Hun et al 2007).

\section{Conclusion}

Nanosized $\mathrm{BaFe}_{19} \mathrm{O}_{12}$ particles were synthesized using self-propagating low-temperature combustion route. The results obtained from crystallite size from XRD and TEM images confirm the nanocrystalline nature of the synthesized products. The results suggest that the self-propagating low-temperature combustion method is an effective pathway for producing high-quality ferrite nanosized powder.

\section{Acknowledgements}

The authors wish to thank University Grants Commission (UGC), Innovative Programme, New Delhi, for financial assistance.

\section{References}

Barb D, Diamandescu L and Rusi A 1986 J. Mater. Sci. 21 1118

Basavaraja S, Vijayananad H, Venkataraman A, Deshpande U P and Shripathi T 2007 Synth. React. Inorg. Met-Org. NanoMetal Chem. 37409

Benito G, Morales M P, Requena J, Raposo V, Vazquez M and Moya J S 2001 J. Magn. Magn. Mater. 23465

Cornell R M and Schwertmann U 1996 The iron oxides: structure, properties, reactions, occurrence and uses (VCH: Weinheim)

Hun X, Zhaohui L, Xuxu W and Xianzhi F 2007 Mater. Lett. 61 347

Jacobo S E, Blesa M A, Domingo-Pascual C and RodpiguezClemente R 1997 J. Mater. Sci. 321025

Kojima H and Wohlfarth E P 1982 Ferromagnetic materials (Amsterdam: North Holland) p. 305

Kubo O, Ido T and Yokoyama H 1982 IEEE Trans. Magn. 18 1122

Lagashetty A, Havanoor V, Basavaraja S and Venkataraman S 2005 Bull. Mater. Sci. 28477

Liu X, Wang J, Gan L M, Ng S C and Ding J 1998 J. Magn. Magn. Mater. 184344

Lucchini E, Meriani S and Slokar G 1983 J. Mater. Sci. 18 1331

Patil K C, Aruna S T and Ekambaram S 1997 Curr. Opin. Solid State Mater. Sci. 2158

Qiu J X, Liang L and Gu M Y 2005 Mater. Sci. Eng. A393 361

Roos W 1980 J. Am. Ceram. Soc. 63601

Shirk B T and Buessem W R 1970 J. Am. Ceram. Soc. 53192

Stablin H and Wohlfarth E P 1982 Ferromagnetic materials (North-Holland, Amsterdam) Vol. 3, Ch. 7

Surig C, Hempel K A and Bonnenberg D 1994 IEEE Trans. Magn. 304092

Venkataraman A, Hiremath V A, Date S K and Kulkarni S D 2001 Bull. Mater. Sci. 24617

Zheng Z, Guo B and Mei X 1989 J. Magn. Magn. Mater. 7873

Zhong W, Ding W, Zhang N, Hong J, Yan Q and Du Y 1997 J. Magn. Magn. Mater. 198196 